\title{
Article \\ A Case of Trauma-Induced Falciformispora lignatilis Eumycetoma in a Renal Transplant Recipient
}

\author{
Maxwell Olenski ${ }^{1,2, *}$, Catriona Halliday ${ }^{3}{ }^{(D}$, James Gullifer ${ }^{4}$, Elena Martinez ${ }^{3}$, Amy Crowe ${ }^{1,2}$, Harsha Sheorey $^{2}$ \\ and Jonathan Darby ${ }^{1}$
}

1 Infectious Diseases Department, St Vincent's Hospital, Melbourne, VIC 3065, Australia; amy.crowe@svha.org.au (A.C.); jonathan.darby@svha.org.au (J.D.)

2 Microbiology Department, St Vincent's Hospital, Melbourne, VIC 3065, Australia; harsha.sheorey@svha.org.au

3 Institute of Clinical Pathology and Medical Research, NSW Health Pathology, Westmead, NSW 2145, Australia; Catriona.Halliday@health.nsw.gov.au (C.H.); elena.martinez@health.nsw.gov.au (E.M.)

4 Pathology Department, St Vincent's Hospital, Melbourne, VIC 3065, Australia; james.gullifer@svha.org.au

* Correspondence: maxwell.olenski@nt.gov.au

Citation: Olenski, M.; Halliday, C.; Gullifer, J.; Martinez, E.; Crowe, A.; Sheorey, H.; Darby, J. A Case of Trauma-Induced Falciformispora lignatilis Eumycetoma in a Renal Transplant Recipient. Trop. Med. Infect. Dis. 2021, 6, 144. https:// doi.org/10.3390/tropicalmed6030144

Academic Editor: John Frean

Received: 9 May 2021

Accepted: 26 May 2021

Published: 3 August 2021

Publisher's Note: MDPI stays neutral with regard to jurisdictional claims in published maps and institutional affiliations.

Copyright: (c) 2021 by the authors. Licensee MDPI, Basel, Switzerland. This article is an open access article distributed under the terms and conditions of the Creative Commons Attribution (CC BY) license (https:/ / creativecommons.org/licenses/by/ $4.0 /)$.

\begin{abstract}
Mycetoma is a chronic, granulomatous, subcutaneous infection caused by several species of fungi and soil-inhabiting bacteria, and is divided into eumycetoma and actinomycetoma, respectively. Endemicity is described with worldwide distribution within the "mycetoma belt"; however, the global burden is ill-defined. Mycetoma is rare in Australia, with only a few published case reports. Over time, the breadth of eumycetoma pathogens has expanded with local epidemiology accounting for variations in regional prevalence. Direct inoculation of pathogens typically heralds the triad of subcutaneous mass, sinus formation and discharging grains. We describe a case of eumycetoma in a 48-year-old male Filipino renal transplant recipient who presented with a painless slow-growing elbow lesion. Ultrasonography revealed two ovoid masses and surgical excision ensued. Histopathology revealed necrotising granulomata with numerous chestnut-brown thick-walled cells, septate hyphae, and occasional grains. On suspicion of localised chromoblastomycosis, the isolate was sent to a reference laboratory which identified the fungus as Falciformispora lignatilis, an organism not hitherto associated with human infection. Amongst the solid organ transplant cohort, similar atypical presentations have been described. Clinicians need to consider eumycetoma where an epidemiological link with the tropics exists, especially in atypical presentations in transplant recipients, including absent preceding trauma.
\end{abstract}

Keywords: mycology; mycetoma; eumycetoma; transplant; immunity

\section{Introduction}

Mycetoma is a chronic, granulomatous, subcutaneous infection caused by several species of fungi and soil-inhabiting bacteria, and is divided into eumycetoma and actinomycetoma, respectively. It is endemic within the "mycetoma belt" - ranging from $30^{\circ} \mathrm{N}$ and $15^{\circ} \mathrm{S}$-however, the global burden is ill-defined, and mycetoma was recognised as a neglected tropical disease by the World Health Organisation in 2016 [1,2]. First described in India, other high incidence countries include Sudan, Somalia, and Mexico [3]. Direct inoculation of causative pathogens typically heralds grain formation within the skin and soft tissues, with progression to subcutaneous nodules, masses and suppuration via sinus tracts [3]. Although mycetoma typically affects the lower limbs, lesions can develop at other sites including the arms, hands and torso.

Mycetoma is rare in Australia, with only a few published case reports [4]. We describe a novel pathogen in a case of eumycetoma in a renal transplant recipient. 


\section{Case Report}

A 48-year-old male was admitted to a tertiary referral centre for elective excision of a right-sided elbow lesion that had developed over four months.

The patient was known to the Nephrology Unit following a renal transplant in 2017 for end-stage kidney disease in the context of primary focal segmental glomerulosclerosis. The initial period of post-transplant immunosuppression was complicated by pulmonary aspergillosis, for which he completed six months of voriconazole therapy with significant interval clinical and radiological improvement as of November 2018.

Other comorbidities included well-controlled hypertension, dyslipidaemia, steroidinduced osteoporosis and gastro-oesophageal reflux. Immunosuppressive therapy included $5 \mathrm{mg}$ of prednisolone daily, everolimus $0.5 \mathrm{mg}$ twice daily, and $1 \mathrm{mg}$ extendedrelease tacrolimus daily.

The patient was born in the Philippines prior to migrating to Australia at age 36, with biannual return trips to visit friends and family. He was neither a smoker nor drank alcohol to excess, and was previously employed in maintenance. He reported no exposure to mangroves or fishing, and did not spend significant time gardening.

The patient initially noticed a painless soft tissue mass on the lateral aspect of his right elbow following minor blunt trauma by a doorknob sustained in Australia in 2019. There was no skin breech, and the lesion grew in size over the ensuing months. Throughout this period he remained systemically well, with no other discernible soft tissue masses.

Baseline blood examination was unremarkable, with stable renal function (Creatinine $169 \mu \mathrm{mol} / \mathrm{L}$ [reference range $64-104 \mu \mathrm{mol} / \mathrm{L}$ ], eGFR $41 \mathrm{~mL} / \mathrm{min} / 1.73 \mathrm{~m}^{2}$ (reference range $\left.>90 \mathrm{~mL} / \mathrm{min} / 1.73 \mathrm{~m}^{2}\right)$ ) and normal inflammatory markers, including white cell indices and a C-reactive protein $<5 \mathrm{mg} / \mathrm{L}$ (reference range $<5 \mathrm{mg} / \mathrm{L}$ ).

Ultrasonography revealed two small circumscribed ovoid masses, suggestive of reactive lymphadenopathy (Figure 1A). Following surgical review, a $1.5 \mathrm{~cm}$ mobile mass was removed which was felt to macroscopically to represent reactive lymphadenopathy. The tissue was set up for routine, mycobacterial and fungal culture, and sent for histopathological examination. No organisms were seen nor cultured from Gram and Zeihl-Neelson stains; however, filamentous fungi were identified on Blankophor preparation.

Histopathological examination revealed extensive necrotising granulomatous reaction with a mixed acute and chronic inflammatory cell population, including neutrophils and multi-nucleated giant cells. The granulomata contained numerous chestnut-brown thickwalled cells, consistent with Medlar bodies, as well as septate hyphae, and occasional grain formation. Periodic acid-Schiff (PAS) staining showed these elements to be PAS-positive, consistent with fungal origin (Figure 1B,C).

On suspicion that the lesion represented a localised chromoblastomycosis, the specimen was sent to the Mycology Laboratory at the Centre for Infectious Diseases and Microbiology Laboratory Services (ICPMR-NSW Health Pathology, Westmead Hospital, NSW) for culture and identification. After 10 days, scant growth was observed on Sabouraud's dextrose agar containing antibiotics at $30^{\circ} \mathrm{C}$, and attempts at inducing sporulation proved fruitless with nondescript fungal hyphae seen on lactophenol cotton blue staining. After a further 4 days, velvety colony growth was observed, which was radially folded, initially marble white and becoming pale grey to purple, with brown exudate produced on the colony surface and dark brown reverse (Figure 1D). 


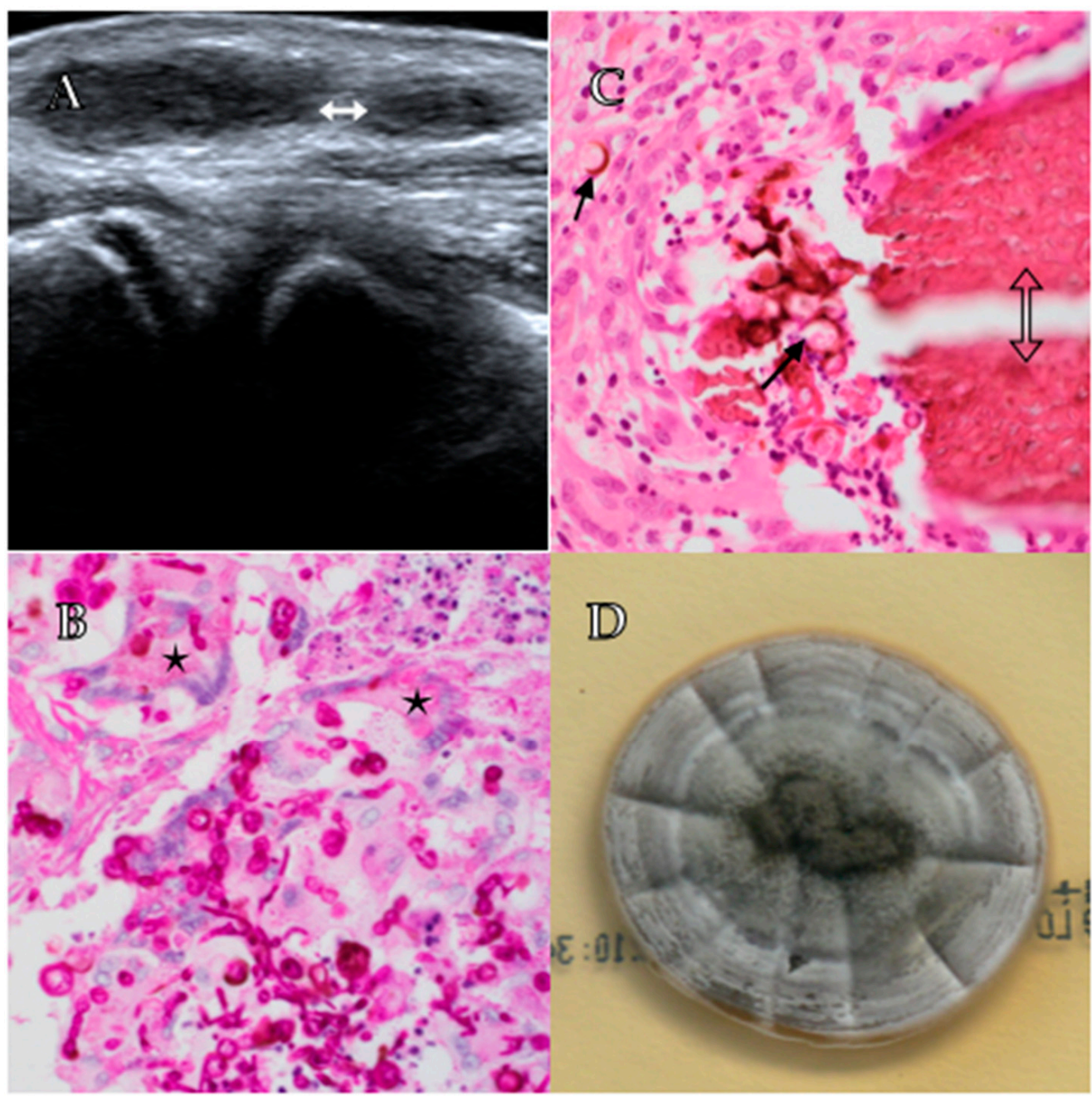

Figure 1. Panel (A) shows a right elbow ultrasound demonstrating two small ovoid lesions (white double-headed arrow). Panel (B) shows septate hyphae and multinucleated giant cells containing fungal elements (stars) at $600 \times$ power on PAS staining. Panel (C) shows a grain (hollow doubleheaded arrow) with surrounding thick walled, brown fungal cells (arrows) at $600 \times$ power on H\&E staining. Panel (D) shows fungal growth after 14 days on Sabouraud's dextrose agar demonstrating grey and purple colonies with radial folding.

For species identification, the internal transcribed spacer (ITS) 1, 5.8S and ITS2 regions, and the D1/D2 region of the $28 S$ (large subunit) rDNA gene were amplified by PCR using previously published primers and protocols (CLSI MM18). Using the BLASTn search within the Westerdijk Fungal Biodiversity Institute Database (https:/ /wi.knaw.nl/page/ Pairwise_alignment, accessed on 20 May 2020) the sequences of the resulting ITS amplicon (GenBank MZ268113) showed $99.4 \%$ identity (529/532 base pairs) to Falciformispora lignatilis (KF432942). The next closest match was to Falciformispora tompkinsii (KF015670) with 96.5\% identity (464/481 base pairs). Although the D1/D2 regions are more conserved, the sequencing results (542 base pairs, GenBank MZ268119) supported the identification of F. lignatilis with $100 \%$ identity to GU371826.1 and $99 \%$ identity (539/542) to F. tompkinsii (MH8792969.1). Partial 28S and ITS sequences for reference Falciformispora isolates and the clinical isolate were concatenated, aligned and a Neighbour-joining tree were constructed using Geneious Prime (version 11.0.3) (Figure 2).

Antifungal susceptibility testing was performed using the Sensititre ${ }^{\mathrm{TM}}$ YeastOne $^{\mathrm{TM}}$ YO10 plate (ThermoFisher Scientific) which is based on Clinical and Laboratory Standards Institute (CLSI) methodology, with numerous studies showing reproducibility and good correlation between Sensititre ${ }^{\mathrm{TM}}$ and CLSI for non-Aspergillus moulds [5]. Un- 
fortunately, no MICs were able to be generated due to poor growth in the Sensititre ${ }^{\mathrm{TM}}$ YeastOne ${ }^{\mathrm{TM}}$ broth.

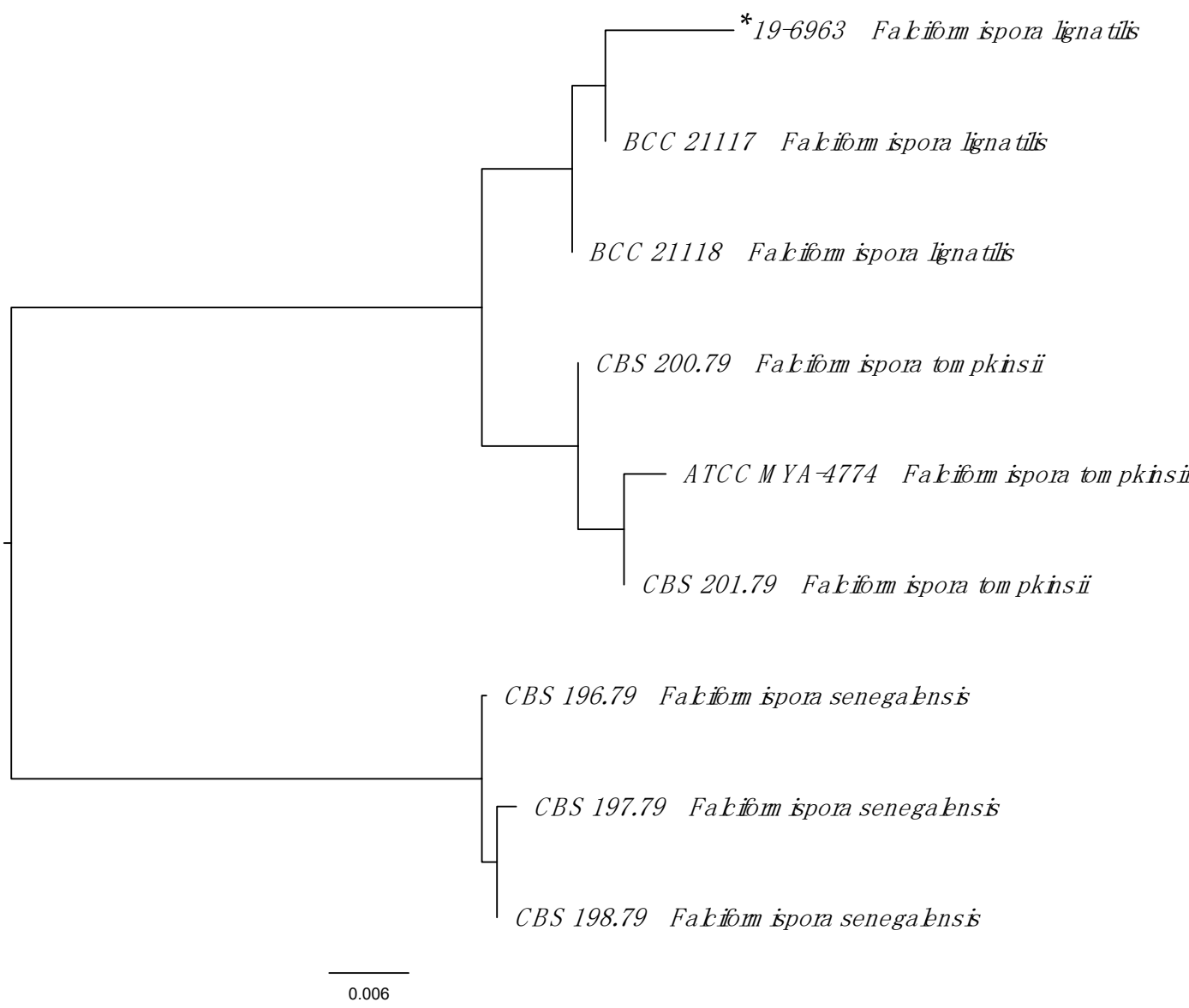

Figure 2. Phylogenetic tree of Falciformispora species reported to cause eumycetoma. The Neighbour-joining tree was constructed from combined partial $28 S$ and internal transcribed spacer sequences. See Ahmed et al. [6] for a more comprehensive phylogenetic overview of all agents of eumycetoma. ${ }^{*}$ Indicates clinical strain.

The patient was commenced on $300 \mathrm{mg}$ of delayed-release oral posaconazole daily for an intended 6-month course, with monitoring of both his posaconazole and tacrolimus levels throughout the duration of therapy.

\section{Discussion}

Eumycetoma tends to affect people living in tropical and subtropical regions, though sporadic cases have been reported worldwide including in temperate regions. As such, risk factors for acquisition include environmental exposure to causative agents, inherited predisposition to infections, and immunosuppression.

Over time, the breadth of pathogens associated with eumycetoma has continued to widen [2]. At least 40 dematiaceous fungi causing eumycetoma have been described and are divided based on the pigment of grains they produce (Table 1). Local epidemiology, including climate, vegetation, rainfall and soil type account for variations in prevalence across regions. 
Table 1. Causative agents of eumycetoma.

\begin{tabular}{cc}
\hline Grain Colour & Causative Organism \\
\hline Black & $\begin{array}{c}\text { Madurella spp. (M. mycetomatis, M. fahali, M. pseudomycetomatis, } \\
\text { M. tropicana) }\end{array}$ \\
\hline Falciformispora (formerly Lepstosphaeria) spp. (F. senegalensis, F. \\
tompkinsi, F. lignatilis)
\end{tabular}

Modified from Ahmed et al. [7].

All fungi known to cause eumycetoma belong to the phylum Ascomycota. Amongst the order Pleosporales, based on multi-gene phylogeny, Leptosphaeria senegalensis and Leptosphaeria tompkinsii were found to cluster with the Trematosphaeriaceae-with Falciformispora lignatilis the closest relative-and have thus been designated Falciformispora senegalensis and Falciformispora tompkinsii, respectively [8]. F. lignatilis has thus far only been recovered from mangrove wood, terrestrial oil palm and fresh water decorticated woody debris in North America and Thailand [8,9], and, to the best of our knowledge, has not hitherto resulted in human infection.

Traumatic inoculation of eumycetoma pathogens from agricultural exposure typically begets infection, including thorns, plant materials and watery habitats, especially amongst farmers and fishermen. Absence of a known predisposing injury is well described, and even innocuous injury without penetrating trauma may render body regions vulnerable (viz. locus minoris resistentiae). A classic triad of soft tissue mass, sinus tracts and macroscopic grains is useful for establishing a clinical diagnosis. Lesions tend to evolve over months to years, and most frequently involve the feet $(68.7 \%)$, leg $(9.9 \%)$, trunk $(6.1 \%)$ and arm $(4.0 \%)[3]$.

Laboratory diagnosis includes standard fungal culture of grains and sinus fluid to identify associated microbial pathogens [7]. In the absence of sinus tracts or grains, tissue biopsy is needed to evaluate for presence of intralesional grains. Complementary molecularbased diagnostic techniques utilise sequencing of highly conserved regions within the ITS region of causative agents of eumycetoma, and are amplified using panfungal primers. This approach allows comparison with findings catalogues within Genbank, and provides insight into the biology and pathogenicity of such fungi. Indeed, such techniques have allowed for identification of previously underspeciated eumycetoma pathogens [10]. In general, however, such modalities are not available in areas of endemicity.

In addition, three histopathological types of tissue reactions are recognised, which relate the presence or absence of grains to acuity of the inflammatory infiltrate, running the gamut from neutrophilic to granulomatous. Regional imaging to define the extent of disease, including the presence of bony involvement, is also useful.

The current standard of care is a combined medical and surgical approach [11]. Limited antifungal susceptibility data are available for most fungi causing eumycotic mycetoma. Historically, ketoconazole and itraconazole formed the mainstay of eumycetoma antifungal 
therapy, though in vitro susceptibility and in vivo clinical response is variable. In general, novel triazoles have favourable in vitro and in vivo efficacy, though the chasm between in vitro data and clinical response remains agape [12]. Nonetheless, whilst antifungal susceptibilities of different azoles vary amongst aetiological agents, posaconazole appears to have the lowest MIC (range 0.01-1 $\mu \mathrm{g} / \mathrm{mL}$ amongst coelomycetes) [2,6]. The optimal duration of antifungal therapy is currently unknown, though emerging data suggest utility in MRI, PET/CT and ß-D-glucan to monitor for extension and relapse [13].

A number of cases of eumycetoma in solid organ transplant recipients have been described. Meis et al. report a case of Madurella mycetomatis in a renal transplant recipient who migrated to Holland from Curaçao 40 years prior to presentation, whereby he presented with atraumatic foot swelling without sinus tract nor grain formation, diagnosed following surgical excision [14]. Similarly, in $2015 \mathrm{McGrogan}$ et al. present another atypical case of eumycetoma in a Ghanaian man in the absence of trauma, as well as summarise the characteristics of transplant-associated mycetomas [15]. Together with our case, these bolster the need to consider eumycetoma where an epidemiological link with the tropics exists, however remote, as well highlight the oft atypical nature of presentations amongst a transplant cohort, including an absent clinical triad and memory of preceding trauma.

The differential diagnosis of eumycetoma includes a range of pathologies, including foreign body granuloma, cystic lesions and soft tissue neoplasm. In addition, in the absence of sinus tract formation, and in the appropriate clinical and epidemiological setting, sporotrichosis, chromoblastomycosis, cutaneous leishmaniasis and tuberculosis need to be considered [16]. Knowledge of key differentiating features, including epidemiology, mode of acquisition and clinical and histological features is paramount.

\section{Conclusions}

Mycetoma is an important subcutaneous infection in tropical and subtropical countries, often characterised by a clinical triad of subcutaneous mass, sinus formation, and discharging grains. Eumycetoma pathogens are well-described and tend to follow a more indolent course compared to their bacterial counterparts.

We propose Falciforma lignatilis be included as a novel agent of eumycetoma, as well as highlight the atypical nature of presentations amongst solid organ transplant recipients.

Clinicians should be aware of the possibility of mycetoma in the immunosuppressed post-transplant patient who frequents areas of endemicity. Whilst the optimal choice of antifungal agents is currently not known, newer agents such as voriconazole and posaconazole show promise.

Author Contributions: Conceptualization, M.O. and J.D.; Data curation, J.G., E.M. and J.D.; Formal analysis, M.O., H.S., C.H. and J.D.; Investigation, C.H., J.G., E.M., A.C., H.S. and J.D.; Methodology, C.H., A.C. and H.S.; Supervision, J.D.; Writing-Original draft, M.O.; Writing-Review and editing, M.O., C.H., H.S. and J.D. All authors have read and agreed to the published version of the manuscript.

Funding: This research received no external funding.

Institutional Review Board Statement: The study was approved by St Vincent's Hospital (Melbourne) Human Research Ethics Committee (HREC). Case Report Approval Date: 3 August 2021.

Informed Consent Statement: Informed consent was obtained from all subjects involved in the study.

Acknowledgments: Sharon Ford; Nephrologist and Transplant Physician-St Vincent's Hospital, Melbourne. Department of Radiology-St Vincent's Hospital, Melbourne.

Conflicts of Interest: The authors declare no conflict of interest. 


\section{References}

1. Centre for Disease Control. Mycetoma I Fungal Diseases. Available online: https://www.cdc.gov/fungal/diseases/mycetoma/ index.html (accessed on 20 July 2020).

2. Ahmed, A.O.A.; van de Sande, W.W.J.; De Hoog, G.S. Fungi Causing Eumycotic Mycetoma*. In Manual of Clinical Microbiology, 12th ed.; American Society of Microbiology: Washington, DC, USA, 2019; pp. 2261-2277.

3. van de Sande, W.W.J. Global Burden of Human Mycetoma: A Systematic Review and Meta-analysis. PLoS Negl. Trop. Dis. 2013, 7, e2550. [CrossRef] [PubMed]

4. Kalatharan, L.; Kelley, P. Eumycetoma diagnosed in urban Australia. Med. J. Aust. 2020, 212, 107-107.e1. [CrossRef] [PubMed]

5. Kidd, S.; Crawford, L.; Halliday, C. Antifungal Susceptibility Testing and Identification. Infect. Dis. Clin. N. Am. 2021, 35, 313-339. [CrossRef] [PubMed]

6. Ahmed, S.A.; de Hoog, G.S.; Stevens, D.A.; Fahal, A.H.; van de Sande, W.W.J. In vitro antifungal susceptibility of coelomycete agents of black grain eumycetoma to eight antifungals. Med. Mycol. 2015, 53, 295-301. [CrossRef]

7. Ahmed, A.A.; van de Sande, W.; Fahal, A.H. Mycetoma laboratory diagnosis: Review article. PLoS Negl. Trop. Dis. 2017, 11, e0005638. [CrossRef] [PubMed]

8. Ahmed, S.A.; van de Sande, W.W.J.; Stevens, D.A.; Fahal, A.; van Diepeningen, A.D.; Menken, S.B.J.; De Hoog, G. Revision of agents of black-grain eumycetoma in the order Pleosporales. Persoonia Mol. Phylogeny Evol. Fungi 2014, 33, 141-154. [CrossRef] [PubMed]

9. Hyde, K.D. Intertidal mangrove fungi from the west coast of Mexico, including one new genus and two new species. Mycol. Res. 1992, 96, 25-30. [CrossRef]

10. De Hoog, G.S.; Van Diepeningen, A.D.; Mahgoub, E.S.; Van De Sande, W.W.J. New species of Madurella, causative agents of black-grain mycetoma. J. Clin. Microbiol. 2011, 50, 988-994. [CrossRef] [PubMed]

11. Chowdhary, A.; Meis, J.F.; Guarro, J.; de Hoog, G.S.; Kathuria, S.; Arendrup, M.C.; Arikan-Akdagli, S.; Akova, M.; Boekhout, T.; Caira, M.; et al. ESCMID and ECMM joint clinical guidelines for the diagnosis and management of systemic phaeohyphomycosis: Diseases caused by black fungi. Clin. Microbiol. Infect. 2014, 20, 47-75. [CrossRef] [PubMed]

12. Lamoth, F.; Kontoyiannis, D.P. Therapeutic challenges of non-Aspergillus invasive mold infections in immunosuppressed patients. Antimicrob. Agents Chemother. 2019, 63, e01244-19. [CrossRef] [PubMed]

13. Crabol, Y.; Poiree, S.; Bougnoux, M.E.; Maunoury, C.; Barete, S.; Zeller, V.; Arvieux, C.; Pineau, S.; Amazzough, K.; Lecuit, M.; et al. Last Generation Triazoles for Imported Eumycetoma in Eleven Consecutive Adults. PLoS Negl. Trop. Dis. 2014, 8, e3232. [CrossRef] [PubMed]

14. Meis, J.F.G.M.; Schouten, R.A.; Verweij, P.E.; Dolmans, W.; Wetzels, J.F.M. Atypical presentation of Madurella mycetomatis mycetoma in a renal transplant patient. Transpl. Infect. Dis. 2000, 2, 96-98. [CrossRef] [PubMed]

15. Mcgrogan, D.; David, M.D.; Roberts, C.; Borman, A.M.; Nath, J.; Inston, N.G.; Mellor, S. Pseudotumoral presentation of fungating mycetoma caused by Phaeoacremonium fuscum in a renal transplant patient. Transpl. Infect. Dis. 2015, 17, 897-903. [CrossRef] [PubMed]

16. Estrada, R.; Chávez-López, G.; Estrada-Chávez, G.; López-Martínez, R.; Welsh, O. Eumycetoma. Clin. Dermatol. 2012, 30, $389-396$. [CrossRef] [PubMed] 